\begin{tabular}{||l|l||}
\hline \hline $\begin{array}{l}\text { Additional } \\
\text { Information }\end{array}$ & $\begin{array}{l}\text { NOTICE: This is the author's version of a work that was accepted for } \\
\text { publication in International Journal of Plasticity. Changes resulting from the } \\
\text { publishing process, such as peer review, editing, corrections, structural } \\
\text { formatting, and other quality control mechanisms may not be reflected in this } \\
\text { document. Changes may have been made to this work since it was submitted } \\
\text { for publication. A definitive version was subsequently published in International } \\
\text { Journal of Plasticity, Vol. 34, July 2012. doi:10.1016/j.ijplas.2012.01.001 }\end{array}$ \\
\hline $\begin{array}{l}\text { Alternative } \\
\text { Location }\end{array}$ & http://dx.doi.org/10.1016/j.ijplas.2012.01.001 \\
\hline
\end{tabular}




\title{
On the intrinsic hardness of a metallic film/substrate system: indentation size and substrate effects
}

\author{
Z. S. Ma ${ }^{a, b}$, Y. C. Zhou ${ }^{a, b, *}$, S. G. Long ${ }^{a, b}$, C. Lu ${ }^{c}$ \\ ${ }^{a}$ Key Laboratory of Low Dimensional Materials \& Application Technology of Ministry of \\ Education, Xiangtan University, Hunan 411105, China \\ ${ }^{\mathrm{b}}$ Faculty of Materials, Optoelectronics and Physics, Xiangtan University, Hunan 411105 , \\ China \\ ${ }^{\mathrm{c}}$ Department of Mechanical Engineering, Curtin University, Perth, WA 6845, Australia
}

\begin{abstract}
To examine effects of indentation size and substrate on the hardness determination of thin films, two typical types of hard film/soft substrate $(\mathrm{Ni} / \mathrm{Fe})$ and soft film/hard substrate (Al/Si and Al/glass) systems are investigated. A simple model is proposed to predict the intrinsic hardness of thin films, which allows a more accurate fitting to empirical data and the estimation of ultimate film hardness. The model can be used to interpret indentation data and extrapolate the indentation depth-hardness curve to an important region where indentation depth lies between $1 \%$ to 5 times of film thickness. The results are well consistent with the evolving trend of composite hardness obtained from experiments and numerical results by finite element analysis.
\end{abstract}

Keywords: Indentation; Strain gradient effect; Substrate effect; Film/substrate system; Hardness

\footnotetext{
*Corresponding author: Key Laboratory of Low Dimensional Materials \& Application Technology of Ministry of Education, Xiangtan University, Hunan 411105, China.

E-mail address: zhouyc@xtu.edu.cn (Y.C. Zhou)
} 


\section{Introduction}

As is well known, materials or structures with small dimensions behave in a different manner as compared to their bulk counterparts. This becomes significantly important in the case of thin films that are widely used as components in microelectronics and microelectromechanical systems. Thus, a good understanding on their mechanical properties is critical for maintaining the integrity of a film-substrate system. Many metals and alloys with different mechanical properties, such as $\mathrm{Ni}$ (Lamovec et al., 2008), Cu (Conrad and Yang, 2002), Al (Erb et al., 2007), Cu-Ni (Zbib et al., 2011), Cu-Sn (Bai and Chen, 2009), and Co-Ni-Fe (Mishra et al., 2009), can be prepared, however, the design of films with optimal properties is based upon the precise determination of their hardness.

According to the conventional plasticity theory, mechanical properties of a material are independent of its length scale (Aifantis, 1987; Aifantis, 2003; Liu et al., 2010). Thus, the measured hardness should be independent of indentation size. In order to obtain 'film-only' mechanical properties, a commonly used rule-of-thumb is to limit indentation depth to less than $10 \%$ of film thickness (Oliver and Pharr, 1992). However, hardness is size-dependent when the depth of impression is below $50 \mu \mathrm{m}$ (McElhaney et al., 1998; Swadener, 2002; Fredriksson, 2005; Nair et al., 2008; Liu et al., 2008; Cordill et al., 2009). The measured hardness may be double or even triple as indentation depth decreases from about 50 to $1 \mu \mathrm{m}$ (Gao et al., 1999; Hwang et al., 2004; Liu et al., 2005; Abu Al-Rub and Voyiadjis, 2006; Abu Al-Rub, 2007; Lele and Anand, 2009; Lee and Chen, 2010; Voyiadjis et al., 2010). The experimental results show that the smaller the size of indentation, the stronger the solid appears. Thus, the classical theory of continuum plasticity is powerless to mimic these 
microstructural effects. However, in strain gradient plasticity theories recently developed, microstructural and continuum descriptions of plasticity have been successfully combined (Fleck and Hutchinson, 1993; Gao et al., 1999; Huang et al., 2000; Voyiadjis, 2005; Chen et al., 2004; Kysar et al., 2010; Saito and Kysar, 2011; Faghihi and Voyiadjis, 2011), in which flow stress depends not only on strain at a particular point, the same as in the conventional plasticity theory, but also on the strain gradient at the point. The intrinsic hardness of a thin film can be extracted by strain gradient plasticity theories (Nix and Gao, 1998). Here, it is worth noting that measurements of 'film-only' hardness are based on the rule-of-thumb as mentioned above. Obviously, such a condition cannot be realized in thin films with several tens of $\mathrm{nm}$ because of the difficulty in collecting meaningful experimental data (Doener and Nix, 1986; Liu et al., 2003; Shi et al., 2008; Nair et al., 2008) and the unnegligible substrate effect (Oliver and Pharr, 1992; Suresh et al., 1999; Vanimisetti and Narasimhan, 2005; Huang and Rosakis, 2005; Zhang et al., 2007). Therefore, to acquire intrinsic properties of thin films from a larger indentation, it is necessary to know how mechanical properties of substrate affect the hardness measurement of thin films.

Generally speaking, the direct measurement of hardness of thin films is impossible by conventional micro-indentation because substrate participates in plastic deformation during an indentation process (Han et al., 2005; Chen et al., 2007; Lamovec et al., 2008). When the depth of indentation exceeds one tenth of film thickness (Cai and Bangert, 1995), the measured hardness $H_{C}$ includes the combined contribution of substrate and film. To determine the true hardness of a film, it is necessary to separate these two contributions. Many studies have been done on the composite hardness, for example, Jonsson and Hogmark (1984) 
proposed a simple composite hardness model based on area functions of film and substrate.

The model works well for indentation depth more than coating thickness. Furthermore, a volume law-of-mixtures model suggested by Sargent (1979) was taken by Burnett and Rickerby (1987), and Burnett and Page (1984). They used Marsh's expanding spherical cavity model (Marsh, 1964) coupled with an intuitive observation, where a hard coating with a higher yield stress is well bonded to substrate. Recently, based on the concept of work-of-indentation, a number of attempts have also been made (Korsunsky et al., 1998; Tuck et al., 2001) to develop a general analysis on indentation of a thin film-substrate system. These models have well explained most experimental results of thick films; however, there are still many difficulties in extracting the true hardness of very thin films because of their small contribution on hardness in large indentation and the size effect in shallow indentation.

To take the effect of small scale and substrate into account when extracting the intrinsic hardness of thin films, Saha et al. (2001) introduced the mechanism-based strain gradient theory. Using strain gradient and classical plasticity theories, Chen et al. $(2004,2005)$ proved that both the strain gradient and substrate effects exist in nanoindentation of a film-substrate system. To the best of our knowledge, however, there is still not a simple model for the full response of hardness, which includes three stages: (I) the film-only indentation size effect, (II) the transition from film to substrate, and (III) the hardness of substrate.

In this paper, a theoritical model is proposed for describing the whole process of hardness response on indentation depth. The paper is organized as follows. In Section 2, the model is introduced for two typical types of soft film/hard substrate and hard film/soft substrate systems. To consider size and substrate effects, indentation experiments of $\mathrm{Ni} / \mathrm{Fe}$ 
and Al/Si systems (Saha et al., 2001; Saha and Nix, 2002) are studied in Section 3. Then, in Section 4, an indentation model and the finite element analysis are discussed, and experiemntal and simulation results are compared in Section 5. Finally, a brief summary is given in Section 6.

\section{The theoretical model}

As shown in Fig. 1, a bilayer indentation system consists of a homogeneous film of thickness $t$ and a substrate. A sharp, fixed-profile indenter is pressed onto the top surface with load $F$ or penetration depth $h$. The influence volume of elastic and plastic deformation field can be described by a hemisphere of radius $a$.
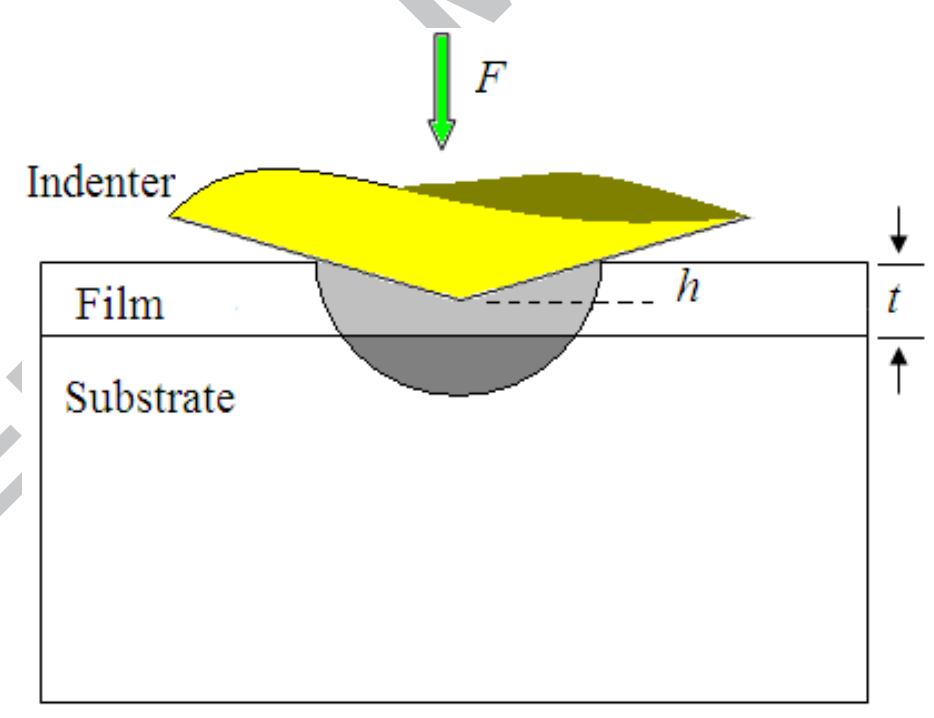

Fig. 1 Schematic of the cross-section in the indentation process of a thin film/substrate system.

To determine the hardness of a thin film, the work-of-indentation-based hardness model 
(Korsunsky et al., 1998) was used to analyze the variation of composite hardness with the relative indentation depth (RID), $\beta=h / t$. According to the model, we have

$$
H_{C}=H_{S}+\frac{H_{F}-H_{S}}{1+\kappa \beta^{2}}
$$

where $H_{C}$ is the apparent composite hardness, $H_{F}$ is the intrinsic film hardness, $H_{S}$ is the substrate hardness, and $\kappa$ is a dimensionless parameter related to the response mode of indentation, defined as $t / \chi$. Here, $\chi$ has the dimension of length. In the case of a cracked film (Korsunsky et al., 1998), we have

$$
\chi \Delta H=3 \gamma \lambda_{1} G_{\mathrm{c}}
$$

while in plastically-deforming films,

$$
\chi \Delta H=\lambda_{2} t H_{\mathrm{F}}
$$

where $\Delta H$ is the hardness enhancement provided by film, $G_{c}$ denotes the through-thickness fracture toughness of film, and $\gamma$ is a material constant. $\lambda_{1}$ and $\lambda_{2}$ are two parameters which describe the dependence of crack length on the material pair, as well as other factors such as indentation depth and diagonal, crack geometry, work-hardening properties of substrate, and interfacial adhesion. In a cracked film, $\kappa$ is proportional to $t$, whereas in plastically-deforming films, $\kappa$ is only weakly dependent of thickness (since $\chi \propto t)$.

A further development on the work-of-indentation model by Tuck et al. (2001) showed that Eq. (1) is incapable of capturing the full extent of hardness response because parameter $\beta$ enters the equation in the form of its square, $\beta^{2}$. They presented a more general formula in order to better describe the variation of hardness $H_{C}$ versus the RID, $\beta$ (Tuck et al., 2001), that is

$$
H_{C}=H_{S}+\frac{H_{F}-H_{S}}{1+\kappa \beta^{\mathrm{X}}}
$$


where $X$ is a power exponent that depends on the deformation mode and geometry.

Considering the indentation size effect of thin films for very small $\beta$, the variable law of hardness follows the Nix-Gao model (Nix and Gao, 1998) based on the mechanism-based strain gradient theory, which can be written as

$$
H_{F}=H_{F 0} \cdot \sqrt{1+\frac{h^{*}}{h}}
$$

where $H_{F}$ is the apparent hardness of thin films rather than the intrinsic hardness defined in Eq.

(2) due to the indentation size effect, and $h^{*}=\frac{27 M^{2}}{2} b \alpha^{2} \cot ^{2} \theta\left(\frac{\mu}{H_{F 0}}\right)^{2}$ is the characteristic length on the order of microns that depends on the properties of indented materials and indenter angle $\theta$. Here, $\mu, b$, and $\alpha$ are the shear modulus, the magnitude of Burgers vector, and an empirical coefficient around 0.3 , respectively. $M$ is the Taylor factor, which acts as an isotropic interpretation of the crystalline anisotropy at the continuum level, and $M=3.06$ for face-centered-cubic metals (Bishop and Hill, 1951; Kocks, 1970). Combining Eqs. (2) and (3), we have

$$
H_{C}=H_{S}+\frac{H_{F 0} \cdot \sqrt{1+\lambda / \beta}-H_{S}}{1+\kappa \beta^{\mathrm{X}}}
$$

where $\lambda$ is the dimensionless characteristic depth, defined as $h^{*} / t$. When $h \rightarrow \infty$ (for large indentation) or $\beta \rightarrow \infty, H_{C}=H_{S}$ represents the hardness of substrate; otherwise when $h \rightarrow 0$ or $\beta \rightarrow 0, H_{C}=H_{F 0}$ represents the hardness of thin film (for shallow indentation).

\section{Experimental}

To experimentally determine the indentation size and substrate effects in a film/substrate system, we chose to study the nanoindentation behavior of pure Ni film on Fe substrate (hard 
film/soft substrate) and pure Al film on Si and glass substrates (soft film/hard substrate).

In general, $\mathrm{Fe}$ has the same (or even higher) hardness as that of $\mathrm{Ni}$, about 1 2 GPa for bulk materials. However, in the case of thin films, the hardness of Ni can reach to $6 \mathrm{GPa}(\mathrm{Ma}$ et al., 2008). A lower carbon steel sheet with $0.3 \mathrm{~mm}$ thickness was used as substrate. A uniform Ni film of $3 \mu \mathrm{m}$ thickness was prepared by the electrodepositing method on both sides of the steel sheet. The Ni thin film thickness and its average grain size are about 3000 nm and $25 \mathrm{~nm}$, respectively, measured by scanning electron microscopy (Ma et al., 2008). Nanoindentation measurements on Ni film were performed by using a TriboIndenter from Hysitron Inc. with a Berkovich indenter. The Ni thin film was tested under the maximum depths ranging from a few tens of nanometers to several micrometers and at least 6 tests were repeated. Due to the very shallow indentation depth and pile-up effect, the indentation size (Nix and Gao, 1998; Ma et al., 2008) and contact area effects must be considered (Lee et al., 2004; Zong et al., 2006) to extract the true mechanical properties of thin films. The actual projected area was measured by a corrected area function at very small indentation depths, and the tip radius of a Berkovich indenter is about $50 \mathrm{~nm}$. To analyze the hardness evolution in a soft film/hard substrate system, experimental results of pure Al films on $\mathrm{Si}$ and glass substrates were adopted (Saha et al., 2001; Saha and Nix, 2002) with thickness of 0.5 and 1 $\mu \mathrm{m}$, respectively.

\section{The indentation model}

\subsection{The constitutive relationship}

According to the Taylor dislocation model (Taylor, 1934), the tension flow stress can be 
expressed as

$$
\sigma_{\text {flow }}=\sqrt{\left[\sigma_{\text {ref }} f\left(\varepsilon^{\mathrm{p}}\right)\right]^{2}+M^{2} \bar{r} \alpha^{2} \mu^{2} b \eta^{\mathrm{p}}}=\sigma_{\text {ref }} \sqrt{f^{2}\left(\varepsilon^{\mathrm{p}}\right)+l \eta^{\mathrm{p}}}
$$

with

$$
l=M^{2} \bar{r} \alpha^{2}\left(\frac{\mu}{\sigma_{\text {ref }}}\right)^{2} b=18 \alpha^{2}\left(\frac{\mu}{\sigma_{\text {ref }}}\right)^{2} b
$$

where $l$ is the intrinsic material length, representing a natural combination of elasticity (shear modulus $\mu$ ), plasticity (reference stress $\sigma_{\text {ref }}$ ), and the atomic spacing (the Burgers vector $b$ ). Due to the different definitions in theoretical models, however, its length scale may also depend on the type of experimental data, such as torsion, bending, and nanoindentation (Fleck et al., 1994; Stolken and Evans, 1998; Aifantis, 1999; Taylor et al., 2002; Tsagrakis et al., 2005). Zbib and Aifantis (2003) suggested that various dislocation arrangements produce different physical behaviors with different gradients and length scales. According to Huang et al. (2006), the intrinsic material length $l$ depends on the choice of the reference stress $\sigma_{\text {ref }}$, a measure of the yield stress. Thus, for a given material, the length scale is chosen as a constant. Here, $\bar{r}$ is the Nye-factor introduced by Arsenlis and Parks (1999) to reflect the scalar measure of geometrically necessary dislocations density in a three dimensional, nonuniform plastic deformation, and $\bar{r}$ is around 1.90 for face-centered-cubic polycrystals. $\varepsilon^{\mathrm{p}}$ and $\eta^{\mathrm{p}}$ are the plastic strain and strain gradient, respectively. $f$ is a nondimensional function determined from the uniaxial stress-strain curve, which can be described by densities of statistically stored dislocations $\rho_{\mathrm{S}}$ as, $f\left(\varepsilon^{\mathrm{p}}\right)=M \alpha \mu b \sqrt{\rho_{\mathrm{S}}} / \sigma_{\text {ref }}$ (Nix and Gao, 1998). In addition, for a given material and indenter geometry, $h^{*}$ is the intrinsic material length related to the intrinsic hardness, $H_{\mathrm{F} 0}=3 \sqrt{3} \alpha \mu b \sqrt{\rho_{\mathrm{S}}}$, in strain gradient plasticity. Therefore, $f$ and $h^{*}$ are two parameters that are related to $\rho_{\mathrm{S}}$. 
The uniaxial stress-plastic strain relationship can be written as (Huang et al., 2004)

$$
\dot{\mathcal{\varepsilon}}^{\mathrm{p}}=\dot{\varepsilon}\left[\frac{\sigma}{\sigma_{\text {ref }} f\left(\varepsilon^{\mathrm{p}}\right)}\right]^{m}
$$

where $\dot{\mathcal{E}}^{\mathrm{p}}$ is the plastic strain rate, $\dot{\mathcal{E}}$ is the effective strain rate, and $m$ is the rate-sensitivity exponent. The uniaxial stress-strain relationship has been studied by Huang et al. (2004) with different rate sensitivity exponents, such as $m=5,20$, and $\infty$. They found that there is almost no difference between the curves of $m=20$ and $m=\infty$. Therefore, $m=20$ was used in finite element model. The volumetric strain rate $\dot{\varepsilon}_{k k}$ and deviatoric strain rate $\dot{\varepsilon}_{i j}^{\prime}$ in the theory of mechanism-based strain gradient plasticity (CMSG) are related to the stress rate in the same way as in classical plasticity, i.e.,

$$
\begin{gathered}
\dot{\varepsilon}_{k k}=\frac{\dot{\sigma}_{k k}}{3 K} \\
\dot{\varepsilon}_{i j}^{\prime}=\dot{\varepsilon}_{i j}^{\mathrm{e}}+\dot{\varepsilon}_{i j}^{\mathrm{p}}=\frac{\dot{\sigma}_{i j}^{\prime}}{2 \mu}+\frac{3 \dot{\varepsilon}^{\mathrm{p}}}{2 \sigma_{\mathrm{e}}} \sigma_{i j}^{\prime}
\end{gathered}
$$

where $K$ and $\mu$ are the elastic bulk and shear moduli, $\dot{\varepsilon}_{i j}^{\prime \mathrm{e}}$ and $\dot{\varepsilon}_{i j}^{\mathrm{p}}$ are the elastic deviatoric and plastic strain rates, respectively, $\sigma_{i j}^{\prime}$ is the deviatoric stress, and $\sigma_{\mathrm{e}}=\sqrt{3 \sigma_{i j}^{\prime} \sigma_{i j}^{\prime} / 2}$ is the effective stress. The effective plastic strain rate $\dot{\varepsilon}^{\mathrm{p}}=\sqrt{2 \dot{\varepsilon}_{i j}^{\mathrm{p}} \dot{\varepsilon}_{i j}^{\mathrm{p}} / 3}$ can be obtained from Eqs. (5) and (7), and we have

$$
\dot{\mathcal{E}}^{\mathrm{p}}=\dot{\varepsilon}\left(\frac{\sigma_{\mathrm{e}}}{\sigma_{\text {flow }}}\right)^{m}=\dot{\varepsilon}\left(\frac{\sigma_{\mathrm{e}}}{\sigma_{\text {ref }} \sqrt{f^{2}\left(\mathcal{\varepsilon}^{\mathrm{p}}\right)+l \eta^{\mathrm{p}}}}\right)^{m}
$$

where $\dot{\varepsilon}=\sqrt{2 \varepsilon_{i j}^{\prime} \varepsilon_{i j}^{\prime} / 3}$. In terms of the strain rate, Eqs. (8)-(10) give the stress rate as

$$
\dot{\sigma}_{i j}=K \dot{\varepsilon}_{m m} \delta_{i j}+2 \mu\left\{\dot{\varepsilon}_{i j}^{\prime}-\frac{3 \sigma_{i j}^{\prime} \sigma_{k l}^{\prime}}{2 \sigma_{\mathrm{e}}^{2}}\left[\frac{\sigma_{\mathrm{e}}}{\sigma_{\mathrm{ref}} \sqrt{f^{2}\left(\varepsilon^{\mathrm{p}}\right)+l \eta^{\mathrm{p}}}}\right]^{m} \dot{\varepsilon}_{k l}^{\prime}\right\}
$$

which can be inverted to the strain rate 


$$
\dot{\varepsilon}_{i j}=\frac{\dot{\sigma}_{m m} \delta_{i j}}{9 K}+\frac{\dot{\sigma}_{i j}^{\prime}}{2 \mu}+\frac{\sigma_{i j}^{\prime}}{\sigma_{\mathrm{e}}} \frac{\dot{\sigma}_{\mathrm{e}}}{2 \mu\left\{\left[\frac{\sigma_{\mathrm{ref}} \sqrt{f^{2}\left(\varepsilon^{\mathrm{p}}\right)+l \eta^{\mathrm{p}}}}{\sigma_{\mathrm{e}}}\right]^{m}-1\right\}}
$$

Here, $\dot{\varepsilon}$ is equivalent to $\sigma_{k l}^{\prime} \dot{\varepsilon}_{k l} / \sigma_{\mathrm{e}}$ in the uniaxial tension. The effective plastic strain gradient $\eta^{\mathrm{p}}$ is given by (Gao et al., 1999; Huang et al., 2000)

$$
\eta^{\mathrm{p}}=\int \dot{\eta}^{\mathrm{p}} \mathrm{d} t, \quad \dot{\eta}^{\mathrm{p}}=\sqrt{\frac{1}{4} \dot{\eta}_{i j k}^{\mathrm{p}} \dot{\eta}_{i j k}^{\mathrm{p}}}, \quad \dot{\eta}_{i j k}^{\mathrm{p}}=\dot{\varepsilon}_{i k, j}^{\mathrm{p}}+\dot{\varepsilon}_{j k, i}^{\mathrm{p}}+\dot{\varepsilon}_{i j, k}^{\mathrm{p}}
$$

where $\dot{\varepsilon}_{i j}^{\mathrm{p}}$ is the tensor of plastic strain rate.

\subsection{Finite element model}

The equilibrium and kinematic relationships between strain and displacement as well as the boundary conditions in CMSG are identical to those in classical plasticity theories. This makes it easy and straightforward to implement CMSG in a finite element program such as ABAQUS (Hibbitt et al., 2002) via its USER-MATERIAL subroutine UMAT (Qin et al., 2007).

As shown in Fig. 2, the cone angle of the indenter is $140.6^{\circ}$, which has the same projection area as a Berkovich indenter at the same indentation depth (McElhaney et al., 1998). In finite element analysis, indentation can be simulated by a contact model between a rigid indenter and film with thickness of $3 \mu \mathrm{m}$. The finite sliding, frictionless, hard contact model in ABAQUS was adopted, which allows sliding between two contact surfaces. Actually, the nanoindenter tip has a non-ideal geometry in applications. The influence of indenter tip radius on determination of mechanical properties has been widely studied. For example, Lu and Bogy (1995) showed that there are weak tip and size effects for large depths in 
indentation tests on bulk materials. Xue et al. (2002) proposed that the effect of an indenter tip radius disappears once the contact radius exceeds one half of the radius. Zhang et al. (2004) also found that, due to the effect of indenter tip radius, the Nix-Gao model could not completely describe the variation of hardness with indentation depth less than $100 \mathrm{~nm}$. Recently, the nanoindenter tip bluntness was considered and a modified size-dependent hardness relationship was given based on the geometrically necessary dislocations (Kim et al., 2005). According to their studies, hardness can be determined by $H=P_{\max } / A_{\mathrm{c}}$ with the contact area $A_{\mathrm{c}}$ being defined as $A_{\mathrm{c}}=\pi a^{2}=\pi\left(h_{\mathrm{c}}+\Delta h_{\mathrm{b}}\right)^{2} \tan ^{2} \theta$. Here, $a, h_{\mathrm{c}}$ and $\Delta h_{\mathrm{b}}$ are the contact radius, contact depth and the height difference between sharp and blunt tips, respectively, and $\theta$ is the half angle of indenter.

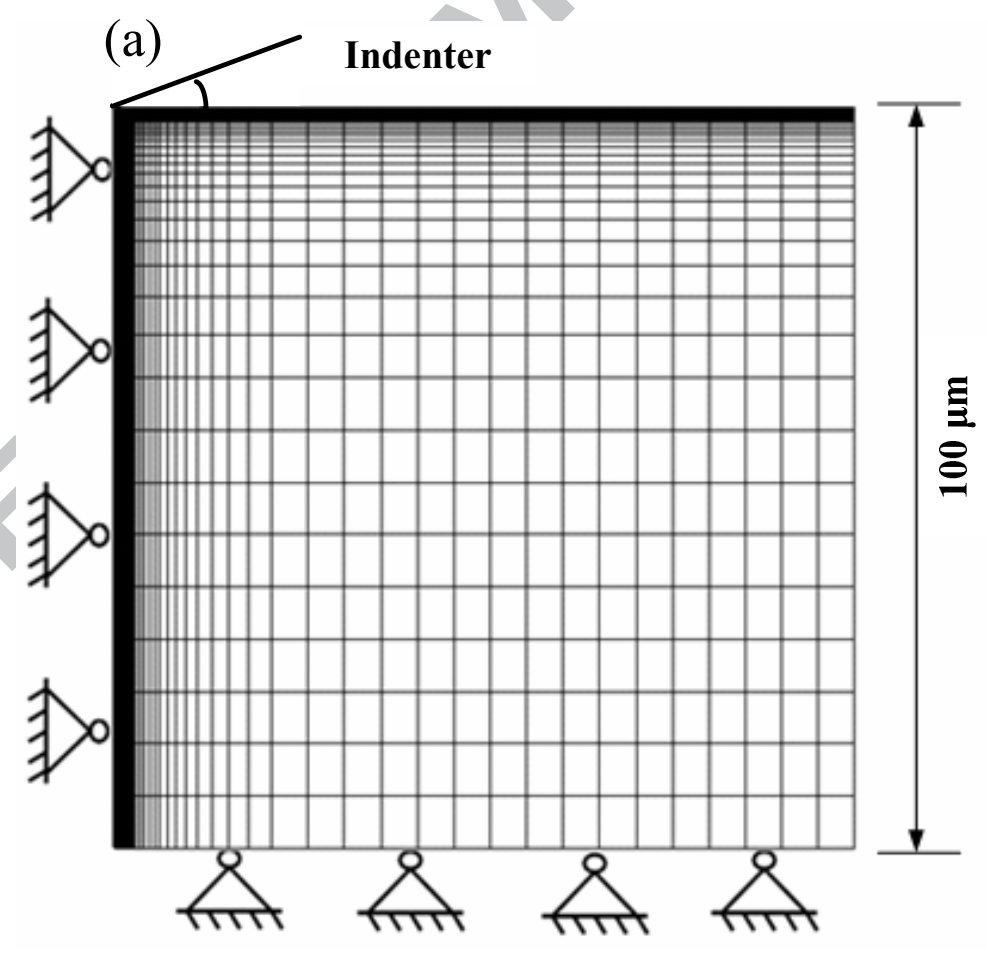




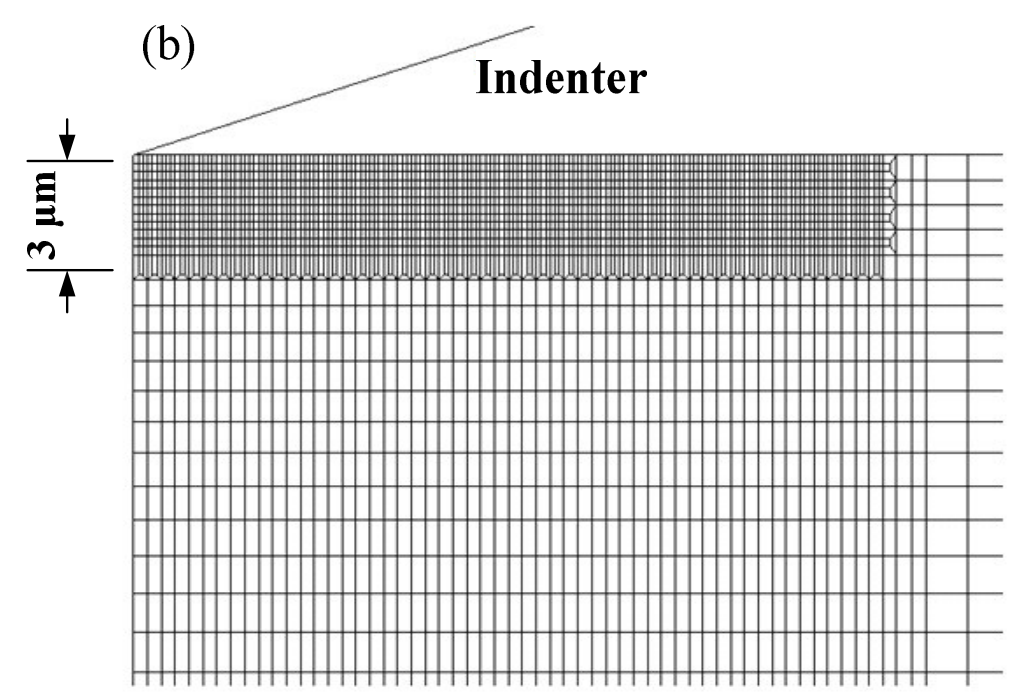

Fig. 2 The finite element model used in simulations: (a) a complete mesh and (b) the enlarged mesh zone near the region of contact.

The stress-strain $(\sigma-\varepsilon)$ relationship under uniaxial tension is assumed as

$$
\varepsilon= \begin{cases}\frac{\sigma}{E}, & \text { for } \sigma \leq \sigma_{\mathrm{y}} \\ \frac{\sigma_{\mathrm{y}}}{E}\left(\frac{\sigma}{\sigma_{\mathrm{y}}}\right)^{\frac{1}{n}}, & \text { others }\end{cases}
$$

where $\sigma_{\mathrm{y}}$ is the yield stress, $n$ is the work hardening exponent, and $E$ and $v$ are Young's modulus and Poisson's ratio, respectively.

\section{Results and discussion}

Based on the experimental procedure in Section 3 and the indentation model in Section 4, we can obtain experimental and simulation data for hard film/soft substrate and soft film/hard substrate systems. Then, these data are analyzed by using the theoretical model of Eq. (4). 


\subsection{Hard film/soft substrate}

As shown in Fig. 3, a knee-shaped profile is observed by a logarithmic scale of RID. The composite hardness levels out of a value closed to substrate hardness. However, there is no clear trend that can be distinguished at very shallow penetration depths due to the indentation size effect. This profile allows us to assess the full range of hardness, which depends upon the thickness of thin films. Therefore, it is necessary to investigate the modes of response over the whole range of RID.

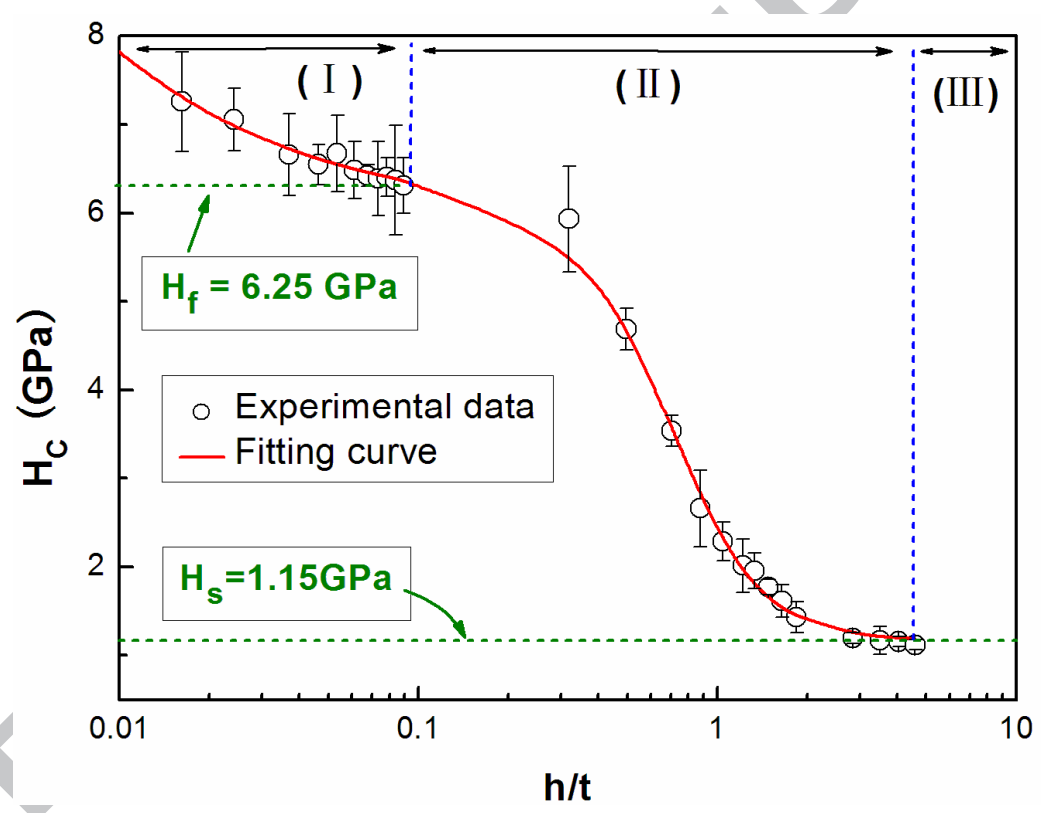

Fig. 3 Experimental results of composite hardness $H_{C}$ as a function of RID for Ni thin film on Fe substrate.

The measured data are marked with diamonds and the model fitting is shown as a solid line in Fig. 3. It is obvious that the data can be well described by Eq. (4), with the correlation coefficient $R^{2}=0.998$ and the fitted intrinsic values of $H_{F 0}=6.25 \mathrm{GPa}$ and $H_{S}=1.15 \mathrm{GPa}$. 
The fitting parameters of $\lambda, \kappa$ and $X$ are listed in Table 1 . Based on the value of $\lambda$, we can obtain the characteristic depth $h^{*}=15 \mathrm{~nm}$, implying the existence of the indentation size effect.

Table 1. Values of the fitted parameters by Eq. (4) in different film/substrate systems.

\begin{tabular}{cccccc}
\hline Film/Substrate & $H_{S}(\mathrm{GPa})$ & $H_{F 0}(\mathrm{GPa})$ & $\lambda$ & $\kappa$ & $X$ \\
\hline $\mathrm{Ni} / \mathrm{Fe}$ & 1.15 & 6.25 & 0.005 & 3.01 & 2.77 \\
$\mathrm{Al} / \mathrm{Glass}$ & 6.8 & 0.45 & 0.26 & 0.035 & 2.49 \\
$\mathrm{Al} / \mathrm{Si}$ & 12.75 & 0.72 & 0.03 & 0.054 & 2.74 \\
Simulation $(\mathrm{Ni} / \mathrm{Fe})$ & 1.20 & 6.07 & 0.007 & 3.76 & 2.51 \\
Simulation $(\mathrm{Al} / \mathrm{Fe})$ & 1.09 & 0.50 & 0.063 & 0.24 & 3.14 \\
\hline
\end{tabular}

\subsection{Soft film/hard substrate}

In terms of the thickness of films, a series of indentation tests were made in $\mathrm{Al}$ films with depths ranging from 250 to $2500 \mathrm{~nm}$. Fig. 4 shows the composite hardness of an $\mathrm{Al}$ film/substrate system (Saha et al., 2001; Saha and Nix, 2002). At small indentation depths, hardness decreases with the increase of depth, as expected by the indentation size effects in bulk materials. At a deeper indentation, hardness reaches a constant of about $0.6 \mathrm{GPa}$ for these two Al films. Then, hardness starts to increase with the increase of indentation depth due to the substrate effect. The plateau in hardness and subsequent increase has not been observed in bulk materials, which may be due to hardening associated with the strong gradients of plastic 
strain in the film between indenter and substrate (Gao et al., 1999; Huang et al., 2000; Saha et al., 2001). Fitting experimental data by Eq. (4), the three stages can be seen from the whole evolving process of composite hardness in Fig. 4. The fitting parameters of $\lambda, \kappa$ and $X$ are listed in Table 1. More importantly, it is worth noting that, as shown in Fig. 4(b), the intrinsic hardness $(0.45 \mathrm{GPa})$ of $\mathrm{Al}$ film with the thickness of $1 \mu \mathrm{m}$ on glass substrate cannot be effectively evaluated from the plateau value (0.6 GPa) (Saha and Nix, 2002). Based on the value of $\lambda$ in Table 1, we can obtain the values of $h^{*}$ of 15 and $260 \mathrm{~nm}$ for Al film/Si substrate and $\mathrm{Al}$ film/glass substrate systems, respectively, implying the existence of indentation size effect.

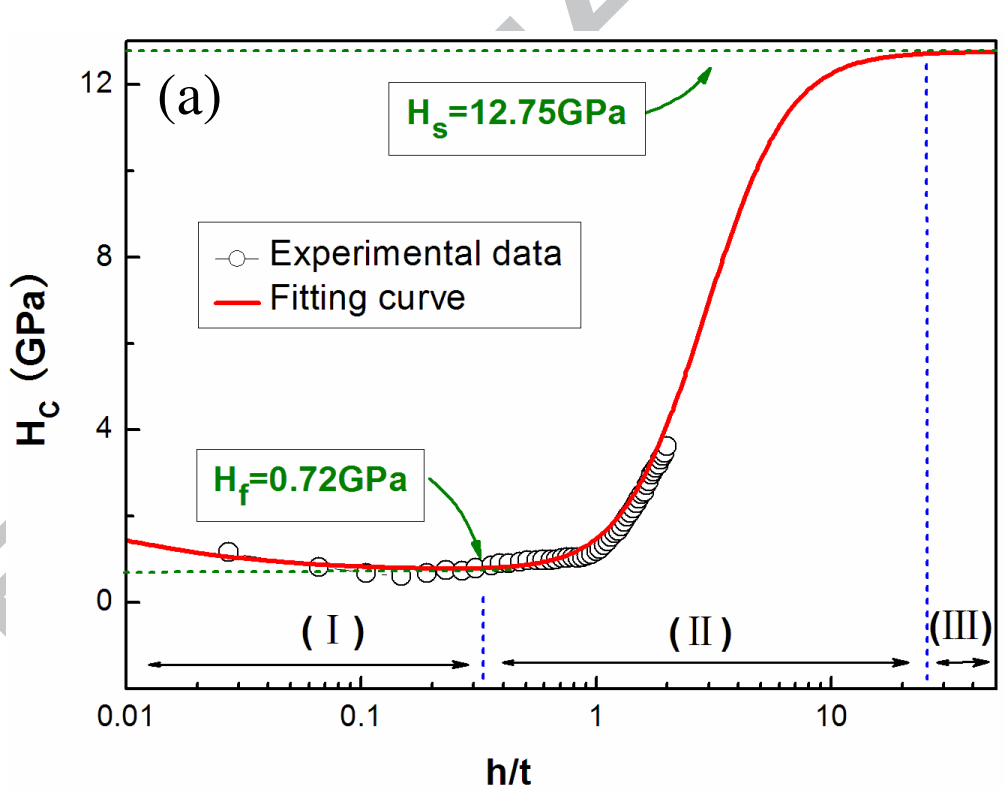




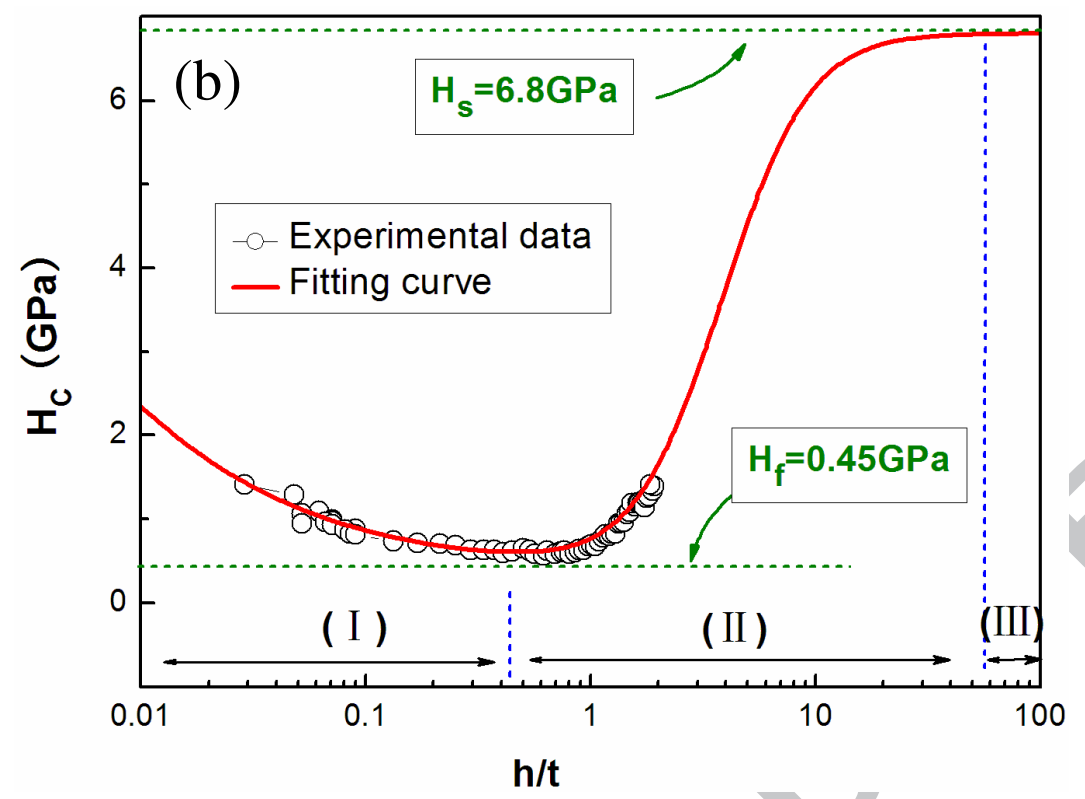

Fig. 4 Composite hardness as a function of RID for (a) a $0.5 \mu \mathrm{m} \mathrm{Al} \mathrm{film/Si} \mathrm{substrate} \mathrm{system}$ and (b) a $1 \mu \mathrm{m} \mathrm{Al} \mathrm{film/glass} \mathrm{substrate} \mathrm{system.}$

As illustrated in Fig. 5, plasticity of thin film dominates the response at low loads, but with the increase of penetration, the combination of film and substrate becomes the main response mode. This process can be separated into three main stages by two critical points $\left(\delta_{1}\right.$ and $\delta_{2}$ ). At the stage I (RID $<\delta_{1}$ ), the local plasticity in film is observed at very shallow indentation depth (i.e., the indentation size effect). When the relative indentation depth approaches a certain value $\delta_{1}$, plastic deformation rises in substrate and the process enters to the next stage. At the stage II $\left(\delta_{1}<\right.$ RID $\left.<\delta_{2}\right)$, the local plasticity of substrate appears at the indentation depth close to interface (i.e., the interaction of indentation size and substrate effects). The contribution of thin film on hardness can be neglected when the relative indentation depth exceeds a certain value $\delta_{2}$. Finally, at the stage III $\left(\mathrm{RID}>\delta_{2}\right)$, plasticity of 
substrate dominates the indentation deformation at deep indentation depth (i.e., the substrate effect).

In coarse-grained metals, plastic deformation is mainly carried by nucleation of dislocations from Frank-Read sources and their motion in individual grains. Grain boundaries hinder the dislocation activity and result in dislocation pile-ups, thereby making metals harder to deform. Reduction in grain size creates more obstacles to dislocation motion due to a larger number of grain boundaries and the yield stress is inversely proportional to the square root of the grain size, i.e., the Hall-Petch relation (Hall, 1951; Petch, 1953). However, in the case of very small grain sizes, the Hall-Petch relation breaks down and even becomes a reverse one. The plastic deformation in nanocrystals is no longer carried by dislocations but instead by grain-boundary sliding and grain rotation (Schiøtz and Jackobsen, 2003; Budrovic et al., 2004; Shan et al., 2004). Similarly, for the very small scale less than $10 \mathrm{~nm}$ in nanoindentation, the reverse Hall-Petch effect also exists in hardness measurements (Saraev and Miller, 2006; Sun et al., 2005). Here, indentation depths are more than $50 \mathrm{~nm}$, which is beyond the range of reverse Hall-Petch effect. Therefore, we do not need to consider the reverse Hall-Petch effect in the model.

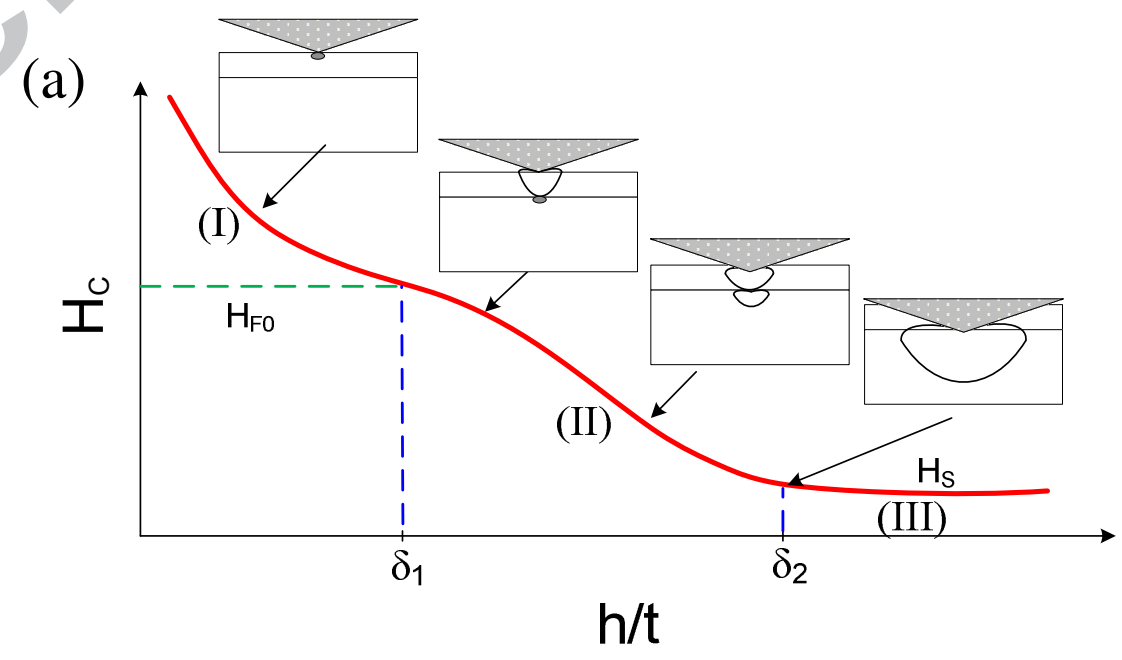




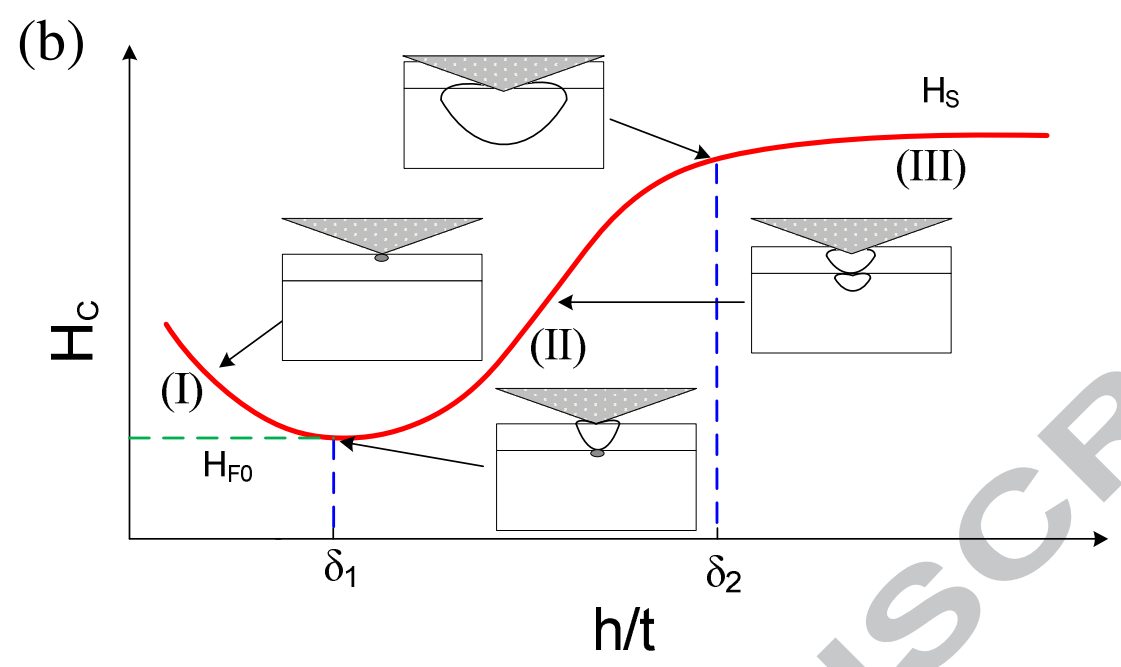

Fig. 5 Schematic of the evolution of plastic response in a film/substrate system with the increase of load during indentation.

\subsection{Numerical results}

To compare the experimental hardness data from $\mathrm{Ni} / \mathrm{Fe}$ and $\mathrm{Al} / \mathrm{Fe}$ (thin film/substrate) systems, it is instructive for us to discuss two extreme cases. One is a very shallow indentation, where the total depth of indentation is much smaller than film thickness, i.e., $h<<t$. At this limit, the significant increase in hardness is due to strain gradient hardening. The other is a deep indentation, where indentation depth is about equal to film thickness, i.e., $h \rightarrow t$. Here, any significant increase or decrease would be caused by the effect of hard or soft substrate.

The parameters of $\alpha$ and $\sigma_{\mathrm{y}}$ can be determined from indentation experiments by the Nix-Gao model. As shown in Eq. (3), the intrinsic hardness $H_{F 0}$ of films is proportional to the yield stress and $h^{*}$ can scale directly with the Taylor coefficient $\alpha$ (Nix and Gao, 1998). The input parameters of three materials $(\mathrm{Ni}, \mathrm{Al}$ and $\mathrm{Fe})$ in finite element simulations are listed 
in Table 2.

Table 2. Mechanical properties of materials (Ni, $\mathrm{Al}$, and $\mathrm{Fe}$ ) predicted by the CMSG theory.

\begin{tabular}{ccccc}
\hline & $E(\mathrm{GPa})$ & $\sigma_{\mathrm{y}}(\mathrm{MPa})$ & $v$ & $n$ \\
\hline $\mathrm{Ni}$ & 225 & 900 & 0.3 & 0.125 \\
$\mathrm{Al}$ & 70 & 300 & 0.28 & 0.05 \\
$\mathrm{Fe}$ & 180 & 400 & 0.3 & 0.1 \\
\hline
\end{tabular}

Fig. 6 shows the indentation composite hardness, predicted by the CMSG theory, versus indentation depth for a $3 \mu \mathrm{m} \mathrm{Ni}$ or $\mathrm{Al}$ film on a Fe substrate. The simulation data are fitted by Eq. (4), indicating a good agreement between the theory and finite element analysis. For shallow indentation, the composite hardness increases with the decrease of depth due to the strain gradient effect. The composite hardness values of $\mathrm{Ni} / \mathrm{Fe}$ and $\mathrm{Al} / \mathrm{Fe}$ systems all tend to Fe hardness in deep indentations. The fitting parameters are given in Table 1. The experimental composite hardness data for a Ni/Fe system are also presented in Fig. 6. It is seen that the composite hardness predicted by the present model agrees well with experimental data over the entire range of indentation depths $(0<h / t \leq 5)$. At small indentation depths in an $\mathrm{Al} / \mathrm{Fe}$ system, hardness decreases with the increase of depth, as expected by indentation size effects in bulk materials. At a deeper indentation, hardness reaches a constant of about $0.5 \mathrm{GPa}$ for the $\mathrm{Al}$ film. Then, hardness starts to increase with the increase of indentation depth due to the substrate effect. Fitting the numerical data by Eq. (4), three stages can be seen in the whole evolving process of composite hardness in Fig. 6. The 
fitting parameters of $\lambda, \kappa$ and $X$ are also listed in Table 1.

As shown in Fig. 6, the composite hardness tends to the hardness of Fe, $1.145 \mathrm{GPa}$, in these two material systems of $\mathrm{Al} / \mathrm{Fe}$ and $\mathrm{Ni} / \mathrm{Fe}$ with large indentation depths.

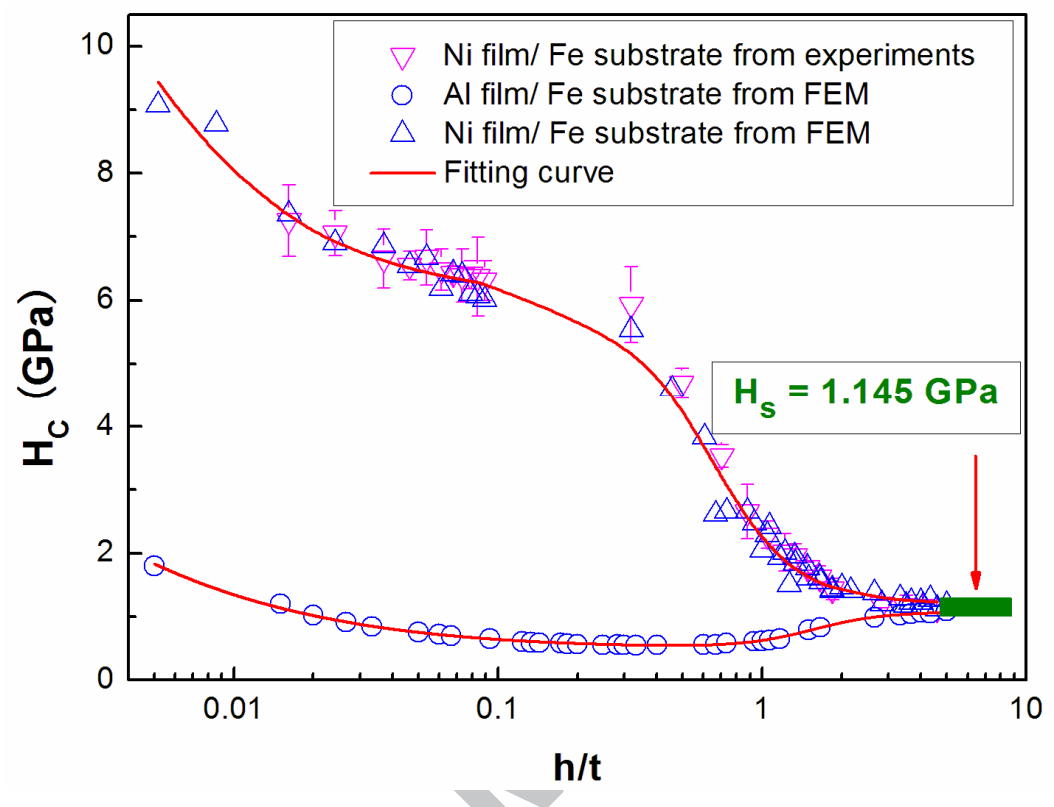

Fig. 6 Composite hardness versus RID in a $3 \mu \mathrm{m} \mathrm{Ni}$ or $\mathrm{Al}$ film on a Fe substrate.

It is worth noting that, however, there are several limitations in the present model:

(i) In a very shallow indentation, the model can not be used to fit hardness due to the reverse Hall-Petch effect;

(ii) The theoretical model and finite element simulation are not suitable to a soft film on a very hard substrate because there is no plastic zone associated with the substrate deformation; and

(iii) The strain gradient effect of substrate has not been taken into account. Therefore, the model cannot be used to describe the tendency of hardness of very thin films (several tens nanometers) on substrate. 


\section{Conclusions}

In summary, the values of composite hardness obtained at different indentation depths are not a constant and the entire process can be separated into three main stages. At stage I, the local plasticity in film is observed (indentation size effect). At stage II, the local plasticity of substrate appears (interaction of indentation size and substrate effects). Finally, at stage III, plasticity of substrate dominates the indentation deformation (substrate effect). The present model can successfully predict the three stages and extract the intrinsic hardness of thin film by introducing a dimensionless characteristic depth related to the indentation size effect. Based on the conventional theory of mechanism-based strain gradient plasticity, numerical results have verified the existence of indentation size effect, which are well agreement with experimental data.

\section{Acknowledgements}

This work was supported by the National Natural Science Foundation of China (Nos. 11102176, 11172258, and 10828205), the Natural Science Foundation of Hunan Province for Innovation Group (No. 09JJ7004), and the Key Special Program for Science and Technology of Hunan Province (No. 2009FJ1002). One of the authors (C. Lu) is also grateful to the support from the Australian Research Council (No. DP0985450). 


\section{References}

Abu Al-Rub R.K., Voyiadjis G.Z., 2006. A physically based gradient plasticity theory. Int. J. Plast. 22, 654-684.

Abu Al-Rub R.K., Voyiadjis G.Z., Bammann D.J., 2007. A thermodynamic based higher-order gradient theory for size dependent plasticity. Int. J. Solids Struct. 44, 2888-2923.

Aifantis E.C., 1987. The physics of plastic deformation. Int. J. Plast. 3, 211-247.

Aifantis E.C., 1999. Strain gradient interpretation of size effects. Int. J. Fract. 95, 299-314.

Aifantis E.C., 2003. Update on a class of gradient theories, Mech. Mater. 35, 259-280.

Arsenlis A., Parks D.M., 1999. Crystallographic aspects of geometrically-necessary and statisticallystored dislocation density. Acta Mater. 47, 1597-1611.

Bai N., Chen X., 2009. A new unified constitutive model with short- and long-range back stress for lead-free solders of Sn-3Ag-0.5Cu and Sn-0.7Cu. Int. J. Plast. 25, 2181-2203

Bishop, J.F.W., Hill, R., 1951. A theoretical derivation of the plastic properties of a polycrystalline facecentered metal. Philos. Mag. 42, 1298-1307.

Budrovic Z., Van Swygenhoven H., Derlet P.M., Van Petegem S., Schmitt B., 2004. Plastic deformation with reversible peak broadening in nanocrystalline nickel. Science 304, 273-6.

Burnett P.J., Page T.F., 1984. Surface softening in silicon by ion implantation. J. Mater. Sci. $19,845-860$.

Burnett P.J., Rickerby D.S., 1987. The mechanical properties of wear-resistant coatings: I: Modelling of hardness behaviour. Thin Solid Films 148, 41-50.

Cai X., Bangert H., 1995. Hardness measurements of thin films-determining the critical ratio 
of depth to thickness using FEM. Thin Solid Films 264, 59-71.

Chen S.H., Liu L., Wang T.C., 2004. Size dependent nanoindentation of a soft film on a hard substrate. Acta Mater. 52, 1089-1095.

Chen S.H., Liu L., Wang T.C., 2005. Investigation of the mechanical properties of thin films by nanoindentation, considering the effects of thickness and different coating-substrate combinations. Surf. Coat. Technol. 191, 25-32.

Chen S.H., Liu L., Wang T.C., 2007. Small scale, grain size and substrate effects in nano-indentation experiment of film-substrate systems. Int. J. Solids Struct. 44, 4492-4504.

Conrad H., Yang D., 2002. Effect of an electric field on the plastic deformation kinetics of electrodeposited $\mathrm{Cu}$ at low and intermediate temperatures. Acta Mater. 50, 2851-2866.

Cordill M.J., Moody N.R., Gerberich W.W., 2009. The role of dislocation walls for nanoindentation to shallow depths. Int. J. Plast. 25, 281-301.

Doener M.F., Nix W.D., 1986. A method for interpreting the data from depth-sensing indentation instruments. J. Mater. Res. 1, 601-608.

Erb U., Aust K.T., Palumbo G., Carl C.K., 2007. Electrodeposited Nanocrystalline Metals, Alloys, and Composites. Nanostructured Materials (Second Edition). Norwich, NY, William Andrew Publishing: 235-292.

Faghihi D., Voyiadjis G.Z., 2011. Determination of nanoindentation size effects and variable material intrinsic legth scale for body-centered cubic metals. Mech. Mater. in press.

Fleck N.A., Hutchinson J.W., 1993. A phenomenological theory for strain gradient effects in plasticity. J. Mech. Phys. Solids 41, 1825-1857. 
Fleck N.A., Muller G.M., Ashby M.F., Hutchinson J.W., 1994. Strain gradient plasticity-theory and experiment. Acta Metall. Mater 42, 475-487.

Fredriksson P., Gudmundson P., 2005. Size-dependent yield strengths of thin films. Int. J. Plast. 21, 1834-1854.

Gao H., Huang Y., Nix W.D., Hutchinson J.W., 1999. Mechanism-based strain gradient plasticity-I. Theory. J. Mech. Phys. Solids 47, 1239-1263.

Hall E.O., 1951. The deformation and ageing of mild steel: III. Discussion of results. Proc. Phys. Soc. Lond B 64, 747-53.

Han S.M., Saha R., Nix W.D., 2005. Determining hardness of thin films in elastically mismatched film-on-substrate systems using nanoindentation. Acta Mater. 54, $1571-1581$.

Hibbitt, Karlsson, Sorenson, 2002. ABAQUS/Standard user's manual version 6.2. Inc.

Huang Y., Gao H., Nix W.D., Hutchinson J.W., 2000. Mechanism-based strain gradient plasticity-II. Analysis. J. Mech. Phys. Solids 48, 99-128.

Huang Y., Qu S., Hwang K.C., Li M., Gao H., 2004. A conventional theory of mechanism-based strain gradient plasticity. Int. J. Plast. 20, 753-782.

Huang Y., Rosakis A.J., 2005. Extension of Stoney's formula to non-uniform temperature distributions in thin film/substrate systems. The case of radial symmetry. J. Mech. Phys. Solids 53, 2483-2500.

Huang Y., Zhang F., Hwang K.C., Nix W.D., Pharr G.M., Feng G., 2006. A model of size effects in nano-indentation. J. Mech. Phys. Solids 54, 1668-1686.

Hwang K.C., Guo Y., Jiang H., Huang Y., Zhuang Z., 2004. The finite deformation theory of 
Taylor-based nonlocal plasticity. Int. J. Plast. 20, 831-839.

Jonsson B., Hogmark S., 1984. Hardness measurements of thin films. Thin Solid Films 114, 257-269.

Kim J.Y., Lee B.W., Read D.T., Kwon D., 2005. Influence of tip bluntness on the size-dependent nanoindentation hardness. Scripta Mater. 52, 353-358.

Kocks, U.F., 1970. The relation between polycrystal deformation and single crystal deformation. Metall. Mater. Trans. 1, 1121-1144.

Korsunsky A.M., Mcgurk M.R., Bull S.J., Page T.F., 1998. On the hardness of coated systems. Surf. Coat. Technol. 99, 171-183.

Kysar J.W., Saito Y., Oztop M.S., Lee D., Huh W.T., 2010. Experimental lower bounds on geometrically necessary dislocation density. Int. J. Plast. 26, 1097-1123.

Lamovec J., Jovic V., Randjelovic D., Aleksic R., Radojevic V., 2008. Analysis of the composite and film hardness of electrodeposited nickel coatings on different substrates. Thin Solid Films 516, 8646-8654.

Lee W.B., Chen Y.P., 2010. Simulation of micro-indentation hardness of FCC single crystals by mechanism-based strain gradient crystal plasticity. Int. J. Plast. 26, 1527-1540.

Lee Y.H., Takashima K., Higo Y., Kwon D., 2004. Prediction of stress directionality from pile-up morphology around remnant indentation. Scripta Mater. 51, 887-891.

Lele S.P., Anand L., 2009. A large-deformation strain-gradient theory for isotropic viscoplastic materials. Int. J. Plast. 25, 420-453.

Liu B., Huang Y., Li M., Hwang K.C., Liu C., 2005. A study of the void size effect based on the Taylor dislocation model. Int. J. Plast. 21, 2107-2122. 
Liu B., Qiu X., Huang Y., Hwang K.C., Li M., Liu C., 2003. The size effect on void growth in ductile materials. J. Mech. Phys. Solids 51, 1171-1187.

Liu Y., Varghese S., Ma J., Yoshino M., Lu H., Komanduri R., 2008. Orientation effects in nanoindentation of single crystal copper. Int. J. Plast. 24, 1990-2015.

Liu Z.L., Zhuang Z., Liu X.M., Zhao X.C., Zhang Z.H., 2011. A dislocation dynamics based higher-order crystal plasticity model and applications on comfined thin-film plasticity. Int. J. Plast. 27, 201-216.

Ma Z.S., Long S.G., Pan Y., Zhou Y.C., 2008. Indentation depth dependence of the mechanical strength of Ni films. J. Appl. Phys. 103, 043512-043516.

Ma Z.S., Long S.G., Zhou Y.C., Pan Y., 2008. Indentation scale dependence of tip-in creep behavior in Ni thin films. Scripta Mater. 59, 195-198.

Marsh D.M., 1964. Plastic Flow in Glass. P. Roy. Soc. Lond. A, 279, 420-435.

Mcelhaney K.W., Vlassak J.J., Nix W.D., 1998. Determination of indenter tip geometry and indentation contact area for depthsensing indentation experiments. J. Mater. Res. 13, $1300-1306$.

Mishra A.C., Sahoo T., Srinivas V., Thakur A.K., 2009. Giant magnetoimpedance in electrodeposited $\mathrm{CoNiFe} / \mathrm{Cu}$ wire: A study on thickness dependence. J. Alloy. Comp. 480, $771-776$.

Nair A.K., Parker E., Gaudreau P., Farkas D., Kriz R.D., 2008. Size effects in indentation response of thin films at the nanoscale: A molecular dynamics study. Int. J. Plast. 24, 2016-2031.

Nix W.D., Gao H., 1998. Indentation size effects in crystalline materials: A law for strain 
gradient plasticity. J. Mech. Phys. Solids 46, 411-425.

Oliver W.C., Pharr G.M., 1992. Improved technique for determining hardness and elastic modulus using load and displacement sensing indentation experiments. J. Mater. Res. 7, 1564-1583.

Petch N.J., 1953. The cleavage of polycrystals. J. Iron Steel Inst. 174, 25-8.

Qin J., Huang Y., Hwang K.C., Song J., Pharr G.M., 2007. The effect of indenter angle on the microindentation hardness. Acta Mater. 55, 6127-6132.

Saha R., Nix W.D., 2002. Effects of the substrate on the determination of thin film mechanical properties by nanoindentation. Acta Mater. 50, 23-38.

Saha R., Xue Z., Huang Y., Nix W.D., 2001. Indentation of a soft metal film on a hard substrate: strain gradient hardening effects. J. Mech. Phys. Solids 49, 1997-2014.

Saito Y., Kysar J.W., 2011. Wedge indentation into elastic-plastic single crystals, 1: asymptotic fields for nearly-flat wedge. Int. J. Plast. 27, 1640-1657.

Saraev D., Miller R.E., 2006. Atomic-scale simulations of nanoindentation-induced plasticity in copper crystals with nanometer-sized nickel coatings. Acta Mater. 54, 33-45.

Sargent P.M., 1979. Ph. D. thesis. University of Cambridge.

Schiøtz J., Jackobsen K.W., 2003. A maximum in the strength of nanocrystalline copper. Science 301, 1357-9.

Shan Z., Stach A.E., Wiezorek J.M.K., Knapp J.A., Follstaedt D.M., Mao S.X., 2004. Grain boundary-mediated plasticity in nanocrystalline nickel. Science 305, 654-7.

Shi Z.F., Huang B., Zhang T.Y., Wu P.D., Hwang K.C., Gao H., 2008. Determination of the microscale stress-strain curve and strain gradient effect from micro-bend of ultra-thin 
film. Int. J. Plast. 24, 1606-1624.

Stolken J.S., Evans A.G., 1998. A microbend test method for measuring the plasticity length scale. Acta. Mater. 46, 5109-5115.

Sun C.Q., Li S., Li C.M., 2005. Impact of Bond Order Loss on Surface and Nanosolid Mechanics. J. Phys. Chem. B 109, 415-423.

Suresh S., Nieh T.G., Choi B.W., 1999. Nano-indentation of copper thin films on silicon substrates. Scripta Mater. 41, 951-957.

Swadener J.G., George E.P., Pharr G.M., 2002. The correlation of the indentation size effect measured with indenters of various shapes. J. Mech. Phys. Solids 50, 681-694.

Taylor G.I., 1934. The mechanism of plastic deformation of crystals. Part I. Theoretical. Proc. R. Soc. Lond. A 145, 362-387.

Taylor M.B., Zbib H.M., Khaleel M.A., 2002. Damage and size effect during superplastic deformation. Int. J. Plast. 18, 415-442.

Tsagrakis I., Efremidis G., Konstantinidis A., Aifantis E.C., 2005. Deformation vs. Flow and Wavelet-Based Models of Gradient Plasticity: Examples of Axial Symmetry. Int. J. Plast. $22,1456-1485$.

Tuck J.R., Korsunsky A.M., Bhat D.G., Bull S.J., 2001. Indentation hardness evaluation of cathodic arc deposited thin hard coatings. Surf. Coat. Technol. 139, 63-74.

Vanimisetti S.K., Narasimhan R., 2005, A numerical analysis of spherical indentation response of thin hard films on soft substrates. Int. J. Solids Struct. 43, 6180-6193.

Voyiadjis, G.Z., Abu Al-Rub, R., 2005. Gradient plasticity theory with a variable length scale parameter. Int. J. Solids Struct. 42, 3998-4029. 
Voyiadjis, G.Z., Pekmezi G., Deliktas B., 2010. Nonlocal gradient-dependent modeling of plasticity with anisotropic hardening. Int. J. Plast. 26, 1335-1356.

Zbib H.M., Aifantis E.C., 2003. Size effects and length scales in gradient plasticity and dislocation dynamics. Scripta Mater. 48, 155-160.

Zbib H.M., Overman C.T., Akasheh F., Bahr D., 2011. Analysis of plastic deformation in nanoscale metallic multilayers with coherent and incoherent interfaces. Int. J. Plast. 27, 1618-1639.

Zhang F., Saha R., Huang Y., Nix W.D., Hwang K.C., Qu S., Li M., 2007. Indentation of a hard film on a soft substrate: strain gradient hardening effects. Int. J. Plast. 23, 25-43.

Zong Z., Lou J., Adewoye O.O., Elmustafa A.A., Hammad F., Soboyejo W.O., 2006. Indentation size effects in the nano- and micro-hardness of fcc single crystal metals. Mater. Sci. Eng. A 434, 178-187. 


\section{Table and figure captions}

Fig. 1. Schematic of the cross-section in the indentation process of a thin film/substrate system.

Fig. 2. The finite element model used in simulations: (a) a complete mesh and (b) the enlarged mesh zone near the region of contact.

Fig. 3. Experimental results of composite hardness $H_{C}$ as a function of RID for Ni thin film on Fe substrate.

Fig. 4. Composite hardness as a function of RID for (a) a $0.5 \mu \mathrm{m}$ Al film/Si substrate system and (b) a $1 \mu \mathrm{m} \mathrm{Al} \mathrm{film/glass} \mathrm{substrate} \mathrm{system.}$

Fig. 5. Schematic of the evolution of plastic response in a film/substrate system with the increase of load during indentation.

Fig. 6. Composite hardness versus RID in a $3 \mu \mathrm{m} \mathrm{Ni}$ or $\mathrm{Al}$ film on a Fe substrate.

Table 1. Values of fitted parameters by Eq. (4) in different film/substrate systems.

Table 2. Mechanical properties of materials ( $\mathrm{Ni}, \mathrm{Al}$, and $\mathrm{Fe}$ ) expected by the CMSG theory. 
1. We investigate the indentation size effect and substrate effect on the indentation measurement.

2. We develop a new method for extracting the intrinsic hardness from indentation.

3. Our model can fit the FEM data from the mechanism-based strain gradient plasticity very well. 